\title{
Disciplining Experience: Francis Bacon's Experimental Series and the Art of \\ Experimenting
}

\author{
Dana Jalobeanu \\ Institute for Research in Humanities, University of Bucharest* \\ dana.jalobeanu@celfis.ro
}

\begin{abstract}
This article is an investigation into the rationale and the structure of order of Francis Bacon's natural and experimental histories. My aim is to show that these natural histories are mainly composed of experimental series, i.e. methodologically organized recordings of experimental inquiries. Bacon's experimental series have a double purpose: heuristic and pedagogical. They direct and encode the "good" experimental practices, while also teaching the neophyte how to become a Baconian experimenter. In this article, I discuss the key elements of Bacon's methodology of experimentation which play an essential role in the generation of experimental series.
\end{abstract}

\section{Introduction}

Francis Bacon's main contribution to the emergence of experimental philosophy was a new way of thinking about the serial character of experimental practices. His natural and experimental histories document his constant attempts to order experimental inquiries. They consist of large collections of lists and series of items, most of which are called "experiments." For Bacon, "experiment" is a generic term; it is used for tests and trials, recipes, ideas of experimental investigations, theoretical observations and methodological

\footnotetext{
* Research for this paper has been supported from PN-II-ID-PCE-2011-3-0719, From natural history to science held by CELFIS, Faculty of Philosophy, University of Bucharest.
} 
suggestions. Experiments never stand alone in a natural history; they come in series of numbered items, sometimes grouped under "heads" and "topics of inquiry." In the Latin natural histories, the structure of "heads" is quite sophisticated: one can find topical inquiries, as, for example "The Motions of Winds," or "Contractions of bodies by actual, external cold." But there are also methodological headings: some experiments belong to lists entitled "History;" others to lists entitled "Directions" [Mandata], "Advice" [Monita], "Major Observations," "Operations," "Intentions," etc. In the posthumous Sylva Sylvarum, experiments are ranged in three categories: "experiments solitary," “experiments in consort," and "promiscuous experiments." The various ways in which such lists of "experiments" were collated have only recently become subject of scholarly investigation. My purpose in this paper is to show that Bacon's series of experiments bear the marks of a particular methodology of experimental investigation. In Bacon's terms, experimental series are the results of a carefully methodized "art" of experimentation called experientia literata. Scholars have long been puzzled by the seemingly contradictory aspects of experientia literata; and a recent stream of papers on the subject rekindled some of the traditional debates over the role and the importance of this art for Bacon's project of a natural and experimental history (Weeks 2006, Jalobeanu 2011, Georgescu 2011, Giglioni 2013, Anstey 2014, Pastorino 2011). My general claim in this paper is that the appropriate context for understanding the complex and intricate nature and functioning of literate experience is provided precisely by the relatively unexplored lists and series of "experiments" so characteristic of Bacon's natural histories. I will show that Bacon's series read as examples of well-ordered, disciplined experimental inquiries, 
i.e., that they are what Bacon hoped his readers will learn in order to be able to assemble properly constructed natural and experimental histories.

Methodological elements come in different shapes and sizes in Bacon's natural and experimental projects. In the Latin natural histories they are more explicit. In the posthumous Sylva Sylvarum they are inbuilt in the experimental series themselves. The first part of this article is a discussion of Bacon's terminology pertaining to experimental practices and experimental recordings. I show that his Latin natural histories contain elements of a relatively unexplored technical vocabulary; and that many of his technical terms refer to a quite sophisticated methodology of recording experimental results and directing experimental practices. In the second part of this paper I discuss an example of an experimental series and show in what way it reads as a "pattern of inquiry," i.e. a methodologically organized recording with heuristic and pedagogical purpose. The third part shows that Bacon's "modes" of literate experience make sense if one reads them as belonging to the same methodology of scientific practice. They offer models of problemsolving, heuristic procedures and recipes for the good guidance of experimental practices and for the assembling of well-ordered experimental series.

\section{Patterns of inquiry}

For Bacon, experiments have major epistemological value. They are used to refute "common conceits," to properly imitate nature, to illustrate, direct and teach (Jalobeanu 2011, 2013). The well-defined results of an experimental inquiry are sometimes said to be beneficial for the well-being of the mind; they act as a "corrective spice," teaching the 
mind how to see nature (OFB XIII 49; SEH IV 421; OFB XII 172-3). ${ }^{1}$ Meanwhile, unguided, untrained experimentation has its own risks; one's mind can be "forever tossed and turned on the waves of experience;" and it takes training for a mind habituated to move in "the darkness of its own notions" to clearly see in the "daylight of experience" (OFB XI, 16-7; XII 173; (Bacon 1987, 76)).

For all these reasons, questions and reflections regarding experimental procedures are prominent in Bacon's natural and experimental histories, where experimental recordings are supplemented by "advice and cautions about the fallacies of things," (OFB XI 15) methodological observations and descriptions of "the way of performing," (OFB XI 469; OFB XII 15) questions, and even speculations (in Bacon’s words, “certain imperfect attempts at the interpretation of causes"). Such methodological reflections figure even in the least structured of Bacon's natural histories, the posthumous Sylva Sylvarum. For example, Bacon glosses on the importance of being highly selective in one's inquiry; on finding mainly "experiments of light," and not "experiments of fruit;" but also on choosing among the experiments of light the right kind of experiments for one's questions. He claims: "The rejection which I continually use of experiments (though it appareth not) is infinite" (SEH II 508). He criticises the "slothful, general and indefinite contemplations" (SEH II 612); the habit to take experiments upon credit (SEH II354), the "grossness of thought" (SEH II 397) and other bad habits of the empirics. By contrast, he proposes "diligent," "careful," and "subtle” inquiries (SEH II 451; 456; 461) into various subjects, such as the production of cold, the "acceleration of time" (SEH II 442ff), generation, growth, maturation, putrefaction, the "more subtle perceptions" of

\footnotetext{
${ }^{1}$ For the references, see the list of abbreviations at the end of this article.
} 
matter (SEH II 602-3). In fact, it is precisely in Sylva that the reader can find one of Bacon's most striking methodological statements. Concluding a series of experiments on the nature, transmission, reflection and amplification of sounds, Bacon remarks that his general purpose was "to make a pattern or precedent of an exact inquisition;"

For we desire that men should learn and perceive, how severe a thing the true inquisition of nature is; and should accustom themselves, by the light of particulars, to enlarge their minds to the amplitude of the world; not reduce the world to the narrowness of their minds. (SEH II 436)

What is this "pattern of an exact inquisition?" The term "true inquisition" [inquisitio legitima] in an important technical term in Bacon's vocabulary; it is usually connected with more advanced, more abstract stages of inquiry belonging to Part IV of Instauratio magna, such as the "ladder" and the "machine of the intellect" (OFB XI 44; OFB XIII 173). But it also functions as an umbrella term, designating more than one stage of the general inquiry which has as its terminus point the elusive and never fully disclosed interpretatio naturae. ${ }^{2}$ Since any research into nature begins with topics of inquiry, a first, preliminary inquiry [inquisitio prima] will have a lot to do with natural history. In

\footnotetext{
${ }^{2}$ Bacon clearly uses the term when describing his interpretatio as the inquisitio legitima \& casta \& severa (OFB XI 44). However, he also uses the term in connection with the anticipations of Part IV and of the natural history of Part III. For interpretations of inquisitio as clearly connected with interpretation see for example (Weeks 2007) More recently, Richard Serjeantson has made a convincing case for the legal origins of inquisition and other related terms (also seen as parts of the process of interpretatio naturae). (Serjeantson 2014).
} 
fact, some of Bacon's later fragments bear the title Historia \& inquisitio. ${ }^{3}$ There are also other, more advanced forms of inquisition, relating to the organization of natural historical material into tables. Some of Bacon's early manuscripts make reference to the "tables of discovery or formulas of legitimate inquisition" [Tabulas Inveniendi sive legitimae inquisitonis formulas] (SEH III 619).

Inquisition also figures prominently in the Latin natural histories, where one can find at least two different forms, or patterns, of inquisition: what Bacon calls "inexact" or "non-systematic" inquisitions [Inquisitio Inartificialis \& in confuso] and their opposite, the systematic and exact inquisitions [Inquisitio Artificialis] (OFB XII 152). For example, in Historia ventorum, Bacon recommends the cursory and non-systematic investigation of the astrological doctrine of winds (OFB XII 23), but a "diligent inquiry" into their limits (OFB XII 25) and a "most diligent inquisition" into their motions (OFB XII 27). A similar systematic and exact inquisition is recommended for the "simulations of winds" [imitamenta ventorum] and the creation of artificial winds. ${ }^{4}$ In terms of results and recordings, all these different inquiries are organized in lists of experiments; however, the list relating to the first, non-systematic kind of inquiry only contains instances of observations and materials taken from ancient and contemporary sources, while the other two kinds of inquiries contain more developed experiments and first-hand observations. The structure of an exact and diligent inquiry is more complex than a mere list of items; it

\footnotetext{
${ }^{3}$ Such is, for example, an interesting fragment first published by William Rawley, containing material corresponding to Centuries II and III of Sylva Sylvarum. Its complete title is Historia et Inquisitio prima, de Sono et auditu, et de forma Soni, et latent processu Soni; sive Sylva Soni et auditus. (Bacon 1658) Another such fragment is Historia \& inquisitio de animato et inanimato, OFB XIII $228 \mathrm{ff.}$

${ }^{4}$ See also Craig Martin's article in this volume.
} 
has branching points, lists within lists, and multiple layers of theoretical elements (Jalobeanu 2015, Chapters 5-7).

In the case of Historia vitae et mortis, the difference between non-systematic and exact inquisitions is even more pronounced. The "exact inquisitions" are said to be organized differently from the non-systematic inquisitions:

Now that I have covered the inquiry by subjects, i.e. inanimate bodies, vegetable bodies, animal and human, I will go deeper, and organize the inquiry by intentions [intentiones]. (OFB XII 236-7)

As Graham Rees pointed out, Bacon used the word "intention" in the classical medical sense [intentio curationis] to mean a general plan of treatment (Rees 2007, liv). To each "intention" Bacon attached particular "operations" [operationes], i.e. set of procedures designed to accomplish the intentions.

Therefore, in an exact inquiry, the steps of the experimental procedure are organized according to a complex structure: a general "intention" (plan) is spelled out in terms of "operations" (sets of procedures destined to lead to accomplishing the intention). These, in turn, are lists of experiments; each experiment on the list contributing to a particular operation. In Historia vitae, for example, Bacon offers a list of 99 "experiments" under the heading "The Operation of the Spirits to keep them young and help recover their strength" (OFB XII 245-271). The list is extremely diverse: it contains medicines, food, drinks, smells, passions of the soul, etc. All these substances are treated as materials for experimental investigations aiming to "put into an old body spirits of the 
kind characteristic of a young one" (OFB XII 245). The "operations" listed in the 99 "experiments" contain "condensations," attempts to "appease and mollify" spirits, to "strengthen" and "enliven" them etc. Preliminary theoretical conclusions are interspersed in the list, and direct the inquiry. For example, one such preliminary conclusion establishes that all the "operations" should "modify" the spirits so that they become "dense, not rare in their substance; persistent, not biting, in their heat; their bulk should suffice for the functions of life, and not excessive, or swollen in their abundance; and steady, not twitchy or uneven in their motion" (OFB XI 247). This operative rule acts also as a principle of selection; it helps the experimenter restrict his empirical investigations to substances and operations eventually leading to the desired effects.

To conclude, one of the most important distinctions between "inexact" or nonsystematic and "exact" inquiries relates precisely to the way experiments are selected. In the more advanced forms of inquiry, the principle of selection is more sophisticated; experiments are not selected "by subject" as in the introductory forms of natural history. They are not selected because they display a certain virtue, process, or appetite. They are selected according to the function they can perform in a more complex research program. Their relevance for certain "intentions" or "operations" is what matters for including a group of experiments in an experimental series.

\section{Methodological elements in natural and experimental history}

Bacon's Latin natural histories also have other, even more explicit, elements of methodology. These are called "advice" $[$ monita $]$ and "directions" [mandata]; and 
constitute technical terms in Bacon's methodological vocabulary. "Directions" offer positive methodological guidance; they are lists of suggestions, ideas, and descriptions of experimental procedures to be further tried and developed. By contrast, "advice" [monita] has a restrictive and cautionary role. Monita are used to teach the researcher what to avoid, where to pay supplementary attention, and how to recognize and understand the limitations of his experiments. ${ }^{5}$ Directions and advice are interspersed in the lists of experiments called "history" [historia]. The proportion between history, direction and advice can vary; in some cases, experiments classified as historia abound; in some others, directions and advice exceed the amount of historia available.

Directions [mandata] are characterized by the presence of multiple suggestions for further development. Here is one example, referring to the contracting effect of "potential cold" [frigor potentiale]:

Take a small bladder of the thinnest skin you can find. Blow it up and tie it off, and bury it in nitre for some days; and then take it out and see if the bladder has gone down at all; and if it has you will know that the cold of the nitre has contracted the air. Do the same experiment by submerging the bladder in quicksilver. But to keep it submerged without pressing down on it you must keep the bladder in position with a thread. (OFB XIII 151)

\footnotetext{
${ }^{5}$ Sometimes advice draws attention to important theoretical distinctions and can play an important heuristic role (OFB XIII 87). In other cases it can explain the limitations of the experimental set-up.
} 
Bacon is using here one of his favourite instruments, an inflated pork bladder, to inquire into the effects of potentially cold substances (such as nitre) upon the enclosed air. ${ }^{6}$ Having previously established that an inflated bladder shrinks under the action of cold; the question is, now, whether potentially cold substances produce the same effect. What happens if, instead of burying the bladder in snow, one places it in nitre, or in quicksilver? Mark that the "direction" recorded above is formulated as a recipe: it gives sufficient details to at least imagine, if not straightforwardly construct the experiments. It offers supplementary advice on how to keep an inflated pork bladder submerged in quicksilver. It even tells the reader what to look for: to see "if the bladder has gone down at all" in the two cases suggested.

Directions [mandata] and advice [monita] play a prominent role in the extremely elaborate structure of a Baconian natural history. They channel the reading, direct the attention towards unsolved problems, problematize, and offer hints and suggestions for further research. ${ }^{7}$ They often display a dynamical structure, which seems to direct the

\footnotetext{
${ }^{6}$ Potential cold and potential heat are terms used to explain "subtle" effects such as that certain substances do not feel hot or cold to the observer and yet they produce heating and cooling effects in certain other substances. Niter and quicksilver are Bacon's favorite example of potentially cold substances (OFB XIII 151). On potential heat and potential cold in Bacon see (Mateiescu 2013)

${ }^{7}$ As Graham Rees has already pointed out, the two natural and experimental histories that Bacon published during his lifetime share a peculiar set of typographical conventions, chosen to create a "signposting of structure and organization of the text." Each particular methodological element is signposted not only with the help of a title, but also by using a different kind of fonts. Similar features can be found in the posthumous Historia densi et rari. See (Rees 2007, xliv).
} 
reader not only towards a better understanding of a text, but to actively engage with the exploration of nature.

To conclude: Bacon's peculiar way of recording experiments in his Latin natural and experimental histories shows his concerns to direct and teach the readers not only how to read natural and experimental histories, but also how to understand the complex interrelations between experimental practices, experimental investigations and natural historical recordings. Signposted methodological elements direct the reading; but they can also function as directions for practice. The resulting lists and series of experiments, advice, observations and directions for further practice composing the Latin natural histories have an important pedagogical function. They keep the mind on the right track and help it to avoid what Bacon claims are the blind and stupid ways of experimenting [modi experimentandi] of the empirics.

Meanwhile, Bacon's methodology of recording experimental practices is not limited to directing the reading. It also has a key role in the process of discovery, as I will show in the following sections of this article.

\section{Experimental series and patterns of inquisition in Sylva Sylvarum: an example}

In order to further inquire into the heuristic of Bacon's natural historical recordings, it is worth having a look at a more particular example of experimental series. In this section I

propose to investigate a particular experimental series recorded in the Sylva Sylvarum, under the name "Experiments in consort touching the version and transmutation of air 
into water." The series consist of seven experiments, apparently very diverse. ${ }^{8}$ The first is a transcription of a Plinian recipe for obtaining fresh water at sea from wool hung around the sides of the ship at night. The second also begins with "it is reported by the ancients" and transcribes a report of the "version of air into water" in sealed caves. ${ }^{9}$ The third records instances of sympathy: fresh wool or cloves can "drink" water from a bowl even if they lie at a certain distance from the water. The fourth is an extension of the same inquiry, showing that sympathetic effects work even if the wool is placed on a closed wooden vessel (SEH II 373). The fifth and the sixth are clearly directions for further experimentation: they extend the discussion to other substances and phenomena, such as the "sweating' of stones and the swelling of wooden doors in cold weather etc. They contain theoretical distinctions and suggest causal explanations. The sixth experiment of the series contains a provisional general rule, i.e., that air always becomes "moist" and "thickened" against a hard body (SEH II 373). The last experiment of the series is also a "direction:" it suggests that one can extend a well-known recipe for turning water into ice (by adding nitre or salt) into a recipe for turning air into water (SEH II 374).

The seven experiments have a similar structure: each begins with a report, continues with a test, and further develops the report either into an experiment properly speaking or into a direction for further experimenting. Here is how the first experiment goes:

\footnotetext{
${ }^{8}$ They are recorded as experiments 72 to 82 in the general list of the one thousands of experiments composing the Sylva Sylvarum; SEH II 372-74. For a more extended discussion see (Jalobeanu 2013).

${ }^{9}$ For a discussion of Bacon's handling of ancient (and modern) sources and the ways he transcribed and worked with borrowed reports see (Jalobeanu 2015 (forthcoming), Rees 1981, Rusu 2013, Jalobeanu 2015).
} 
It is reported by some of the ancients, that sailors have used, every night, to hang fleeces of wool on the sides of their ships, the wool towards the water; and that they have crushed fresh water out of them in the morning, for their use.

This is the initial "experimental report," a recipe borrowed from Pliny's Historia naturalis. ${ }^{10}$ This is further tested and developed into a quantitative experiment:

And thus much we have tried, that a quantity of wool tied loose together, being let down into a deep well, and hanging in the middle, some three fathom from the water for a night in the winter time, increased in weight (as I now remember) to a fifth part.

This reported trial is very condensed. It gives some practical details and the final result, but in a very abridged manner. ${ }^{11}$ In the Historia densi et rari, however, we can find a more "exact" inquiry into the very same subject. There, the paragraph quoted above is developed into a list of three different experiments: the ancient report is followed first by simple test and a tentative causal explanation:

\footnotetext{
${ }^{10}$ The reference, correctly identified by Spedding, is Pliny, Historia naturalis xxxi, 37.

${ }^{11}$ This abridged manner of recording has made the experimentation in Sylva rather obscure for many readers. However, comparative reading of Bacon's recording of experiments in Sylva Sylvarum and the Latin natural histories shows that some of the missing details are often recorded elsewhere.
} 
A woollen fleece lying on the ground for a long while gains weight, which could not happen unless something pneumatic had condensed into something with weight. (OFB XIII 141)

This is further developed into a "careful" and "diligent" trial:

By hanging four ounces of wool to a rope which I let down into a well to a depth of 28 fathoms, yet which still failed by six fathoms to touch the water, I found that in the course of one night the weight of the wool increased to five ounces and one dram; and that evident drops of water clung to the outside of the wool, so that one could as it were wash or moisten one's hands. Now I tried this time and time again and, although the weight varied, it always increased mildly. (OFB XIII 141)

It is clear that what we have in the two natural histories are simply two different recordings of the same experiment: with more quantitative details in the Historia densi et rari $(H D R)$ and with some of the quantitative details omitted in Sylva Sylvarum. In fact, the experiment as recorded in Sylva only preserves the essential details from the more detailed series of trials recorded in $H D R$ : namely that by condensing the water, the wool has increased in weight with $1 / 5$. It is clear that this is an estimate across a number of different experiments, and not an exact measurement. However, if the purpose of the Sylva is to offer a "pattern of exact inquisition," the details recorded are what matters. They are the details one would need, if one attempts to replicate the experiment. 
There are other experiments in the series with a very similar structure and a similar abridged recording. For example, the second experiment begins with a report on air turning into water in sealed, cold caves. In order to test and study further this ancient report, Bacon proposes a "laboratory model" of the described situation. The instrument used is the same inflated bladder I have already discussed in the previous section. Suggestions are again formulated under the form of "directions:"

Try therefore a small bladder hung in snow, and the like in nitre, and the like in quicksilver; and if you find the bladders fallen or shrunk, you may be sure the air is condensed by cold of these bodies; as it would be in a cave under the earth. (SEH II 373)

This list of directions is an abbreviated recording of experiments developed elsewhere. But this time, they are taken to be the illustration of a natural situation. The bladder buried in snow is a "laboratory model" of the cave from the ancient story. And again, Bacon tells the reader what to observe in order to infer "the version of air into water."

In this way, each experiment in the series can function as a pattern of experimental research in a given experimental situation. And the way Bacon achieves this is by developing sub-series of "directions" and "advice" directing further research.

The question remaining is: what is the relation between the seven experiments of the initial series? In the next section I aim to show how they can be seen as being generated one from another, with the help of what Bacon calls the "modes" of literate experience. 


\section{Variation, generalization, extension and other "good ways" of experimentation}

Four of the seven experiments in consort dealing with the "version" of air into water involve placing porous bodies under various conditions: in a well, in the vicinity of vessels containing water, next to solid cold bodies etc. These experiments can be clearly derived one from the other by simple rules, such as the variation of some experimental parameters: the quantity of water, the distance from the water-source, the state of intervening bodies etc. In all cases, we assume that what happens is similar: the water from the vessel first evaporates, and then condenses in the porous fibre of the wool. Another way of varying the experimental parameters is by replacing the water with vinegar and by sealing the vessel containing liquid. The fact that condensation still occurs is taken as proof that the wool is effective not only in condensing surrounding vapours, but also in attracting them. This "attraction" is further investigated in the other two experiments ( 80 and 81$)$. One states that every porous body has the power to "attract" water; this, due to the fact that "tangible bodies have an antipathy with air:"

$[\ldots]$ and if they find any liquid body that is more dense near them, they will draw it; and after they have drawn it, they will condense it more, and in effect incorporate it; for we see that a sponge, or wool, or sugar, or a woollen cloth, being put but in part in water or wine, will draw the liquid higher, and beyond the place where the water or wine cometh. We see also, that wood, lute-strings, 
and the like, do swell in moist seasons; [...] which is a kind of infusion; and is much like to an infusion in water, which will make wood to swell; as we see in the filling of the chops of bowls, by laying them in water. But for that part of these experiments which concerneth attraction, we will reserve it to the proper title of attraction. (SEH II 373)

With respect to previous experiments in the series, this one contains a generalization. It does not talk about wool, but about an entire list of porous bodies: sponges, sugar, woollen cloth, wooden musical instruments, wooden doors, strings etc. All these contain air in their pores; air which, under certain conditions, is replaced by water. Second, Bacon is making a highly theoretical claim: that "tangible bodies have an antipathy with air." Because of this antipathy, they are willing to give air away from their pores, in exchange for water, or for any denser liquid. This claim is part of Bacon's pneumatical matter-theory (Rees 1996, Giglioni 2010, Rusu 2013). Note, however, that Bacon's experimental series is not constructed to test this and like claims. Theoretical assumptions regarding the "appetites" and "sympathies" are taken for granted; they are part of the background knowledge of the experimenter. What the experimenter is testing is the similarity between the behaviour of the given substances when placed in water, and near water. In both situations, wool, sponges, wood, strings etc., become "swollen" and heavier. This is taken as proof that in condensation, the pores of all these substances fill with water in the same way as in infusions (SEH II 373). In a way, it does not matter why this is happening; the empirical similarity grounds analogical reasoning and offers a way to measure the 
effect in both cases. Note also that Bacon distinguishes here between two different effects: the "attraction" porous substances have for water in virtue of their antipathy for air, and their capacity to draw water or moisture if placed very near a source of water, and to "condense it more." Only the second effect is under study in this case and it is precisely this second effect that is further developed and investigated.

What about the experiments that do not feature wool and porous substances? What is the connection between the experiment dealing with the condensation of air in caves, or in bladders and the experiments involving packs of wool and other porous substances placed near the water? One way is to see the second part of the series as a generalization of the more particular experiments with the bladder. Another way is to see them as extending the initial analogy: if the inflated bladder is a laboratory "model" of a cave, porous substances also have enclosed cavities analogous (to some extent) with such inflated bladders.

In conclusion, one can read this particular string of experiments as an experimental series, where subsequent experiments develop from previous ones by the application of methodological procedures such as the (controlled) variation of parameters, generalization, analogical thinking and modelling. These methodological procedures are precisely some of the "modes" of literate experience enumerated by Bacon in De augmentis scientiarum (1623). More precisely, they are what Bacon calls "variation," "production," and "translation." Before explaining how these "modes" of literate experience can be used to generate experimental series, it would be worth having a closer look at Bacon's theoretical justification of the art of literate experience. To this I will now turn. 


\section{Experientia literata: the "good ways" of experimentation}

Bacon was not the first to use the variation of parameters to generate new experiments. This was a quite traditional practice among the empirics. It was also a practice Bacon was very critical of. He criticised simple, "blind" variation and what he called "stupid and illiterate experience," he was also critical of most of the received notions of experiment, ${ }^{12}$ and a good number of received experimental practices. For example, Bacon claims that the explorer of nature "wanders" and gets lost in the "woods of experience" precisely because the "modes of experience" currently in use, are blind and stupid:

[...] those that have been conversant in experience and observation have used, when they have intended to discover the cause of any effect, to fix their consideration narrowly and exactly upon the effect itself with all the circumstances thereof, and to vary the trial thereof as many ways as can be

\footnotetext{
${ }^{12}$ For Bacon, the difference between the two is mainly of intentionality: "mere experience [experientia mera $][\ldots]$ is called accident if it happens by itself, but experiment [experimentum] if it is sought out" (OFB XI 131). Experimentum is used almost invariably in the sense of "trial" and "recipe;" a sense widely spread in the literature on practical mechanics, natural magic and the secrets of nature. Also, experimentum refers to novelty and the "artificial" creation of novel facts. The experiment does not test a theory and it is often quite independent of any given theory. See (Jardine 1974, 136-7, Deleule 1984, 62) Marta Fattori proposes a different interpretation of the couple experience/experiment (Fattori 2012, 180). Meanwhile, Cesare Pastorino has shown the similarities between some of Bacon's experiments from Historia densi et rari and later "event experiments" as recorded by Boyle and Newton. See (Pastorino 2011) On the multiple meaning and functions of Bacon's experiments see (Jalobeanu 2013).
} 
devised; which course amounteth but to a tedious curiosity, and ever breaketh off in wondering and not in knowing; and [...] they have not used to enlarge their observation to match and sort that effect with instances of a diverse subject $[\ldots]$ they have not collected sufficient quantity of particulars, nor them in sufficient certainty and subtility, nor of all several kinds, nor with those advantages and discretions in the entry and noting which are requisite [...] (SEH III 346-7)

In other words, Bacon criticizes simplified methodologies of experimentation, reduced to the mere variation and repetition of an arbitrarily selected and badly limited number of particular cases. He criticizes the unimaginative principle of the selection of particular effects - because one "cannot successfully investigate the nature of anything just by looking at the thing itself" 13 - and the selection of circumstances deemed "relevant" for the production of the effect under study. This is what Bacon calls unguided, vague and uneducated experience [vaga experientia], which, he claims, is a sort of "groping in the dark" (OFB XI 158-9). He claims that in order to avoid the pitfalls of "mere experimentation," one need to make experience "literate," "disciplined" and "educated." Literate experience is "going forward according to a certain law [Experientia lege certa procedet] step by step and steadily" (OFB XI 158-9). It is fully understandable that Bacon's Victorian editors translated experientia literata with learned experience in order to convey precisely this nuance of the advancement and progress made from an

\footnotetext{
${ }^{13}$ See also: OFB XI 111; 143; SEH III 246.
} 
"illiterate" to an educated form of empiricism. ${ }^{14}$ Unlike the illiterate and vague form of experience, literate experience proceeds methodically, according to the law; it contains the "good" ways of experimenting; it is not merely ordered but also "digested" [digesta] and ripe, which means, in Bacon's terms, another way of saying that literate experience is an adequate and mature method of discovery.

In De augmentis scientiarum Bacon formulates eight such 'modes,' or good "ways of experimenting." Their status is somewhat obscure. Scholars have failed to agree whether to read them as rules, practical strategies for doing good research, elements of heuristic, or models of exploratory experimentation (Jardine 1990, Pastorino 2011, Weeks 2007, Georgescu 2011, Jalobeanu 2011, 2013, Giglioni 2013). My proposal is to read them as the "good ways of experimentation" which can be used to produce "patterns of inquiry." I suggest that these "modes" are precisely what is missing in order to understand more clearly how some of Bacon's experimental series were ordered and put together in the first place, and how different they were from contemporary experimental practices.

The first way of experimenting is called "variation" and refers to what we have already seen: to the variation in the "matter," "efficient cause" and the "quantity" involved in a given experimental set-up (SEH IV 413-4). All these variations, if performed methodically, produce series of experiments meant to clarify either a phenomenon or a set of experimental procedures. Bacon's variation differs in many ways from the "blind" variation of the empirics. First, its purpose is to ask questions of

\footnotetext{
${ }^{14}$ Guido Giglioni proposes to read experientia literata in similar terms, as a form of "cognitive literacy," as an educated form of "empiricism." See (Giglioni 2013).
} 
clarification relating to an experiment or a set of experimental procedures. Second, variation does not stand alone; it is merely the first procedure in a set. It establishes a rule, i.e., that it is not "safe to rely on any experiment in nature, unless it has been tried both in greater and in lesser quantities" (SEH IV 415).

The second mode, called "Production" [productio], governs two different ways of producing a new experiment. One is what Bacon calls "by repetition," which means by re-applying the same procedure in the same experimental set-up. For example, we can ask: do we get anything interesting if we repeat one of the experiments of condensation? Can a "further condensation" occur? What happens if the air condensed into water is subject to further condensation? Does it get "thicker than water?" This is, I think, the reason Bacon suggests as an interesting direction of further research to inquire into whether the procedure of turning water into ice would not be relevant for the condensation of air into water (SEH II 374). The second type of "production" is what Bacon calls "by extension." In this case, the repetition involves a change of the experimental set-up and the extension of the initial experiment in another direction. We have seen this type of extension in Bacon's replacement of water with vinegar, and of an open vessel with a sealed barrel. This new experiment is neither a simple variation, nor a mere repetition; it creates a different experimental set-up, where condensation takes place despite the presence of the dividing plank of wood. In a barrel of vinegar, one might imagine that at least a tiny part of the liquid will penetrate through the pores of the wood and make them slightly humid. However, the effect will be barely visible; and the level of liquid in the barrel will be more or less the same. By placing the wool on the top of the barrel, however, the experimenter is producing a visible effect: the level of the liquid in 
the barrel decreases. The wool not only "captures" some moisture already present in the wood, but it is really as if it "drank" some vinegar. This is further extended in another experiment, intended to distinguish between two different effects: condensation of air into water and the "attraction" of water (at a distance). Here the experimenter divides the question into two different parts, files away the part regarding the attraction and concentrates upon the study of condensation per se. ${ }^{15}$

The third "mode" of literate experience, called "translation" [translatio], seems to go in the same direction of "extending" the question and the field of research. This mode governs various ways of translating the experiment from one group of phenomena to another, either within the same field or in a cross-disciplinary manner. All examples formulated by Bacon under this heading involve various forms of analogical thinking. One way of translating experiments is by creating artificial models of natural phenomena. Instead of studying rainbows, we study artificial rainbows produced in a prism. Instead of studying the condensation of air into water in sealed caves, we study the behaviour of an experimental device, the inflated bladder. Producing "artificial models" of natural phenomena is one of the important recurrent features of Bacon's experimental series. Bacon is also interested in building instruments and "technologies" for producing a wide range of effects: like the construction of artificial wind-mills, of wind-carriages. Such technologies are the embodiment of the first three modes of literate experience: they offer the means to produce controlled variations of parameters, to repeat and extend the experiment, and sometimes to translate it into another field.

\footnotetext{
${ }^{15}$ Bacon has many instances of such "attraction” and sympathy in his study of plants. He gives examples of plants capable of "perceiving" where the water is, and even "drink" by attraction (SEH II 489; 498).
} 
The fourth "mode" of literate experience governs what Bacon calls the "inversion of experiment," i.e., a way of reversing the experimental procedure and seeing what happens if we begin with the effect of a given phenomenon and attempt to play with it in search of its causes (SEH IV 418). The fifth mode is called "compulsion" [compulsio] and involves an attempt to measure the range and limits of a certain effect (SEH IV 419). In our series of experiments on condensation, placing the wool on top of a sealed container is a form of applying "compulsion" in order to see whether the "drawing power" of the pack of wool is diminished or extinguished in this way.

The sixth "mode," called "application," means transforming a given experiment into an instrument, or a technology. In other ways, it is a way to transform "pure" into “applied science." For example, Bacon uses the properties of wool to condense the water for developing a practical application: an instrument for measuring humidity (SEH II 605).

The seventh "mode" of literate experience is called "coupling" [copulatio], and it is a conjunction of some of the previous ways of experimenting. The eighth "mode" is called "chances" [sortes]; and means "to try something, not because reason or some experiment leads you to it, but simply because such a thing has never been attempted before" (SEH IV 420). This, however, does not mean "blind" trial and variation; it means moving a step further from everything that has been tried in the past; "leaving no stone of nature unturned:"

For the magnalia of nature generally lie out of the common roads and beaten paths, so that the very absurdity of the thing may sometimes prove of service. 
But if reason go along with it; that is, if it be evident that an experiment of this nature has never been tried, and yet there is great reason why it should be tried; then it is one of the best ways, and plainly shakes out the folds of nature. (SEH IV 420)

Previous interpreters have emphasized the importance of this remnant of randomness in Bacon's theory of experimentation (Giglioni 2013). My suggestion is that one should not be misled by names. Bacon's emphasis is not on chance and randomness but on what is required to get to something new in an experimental inquiry. For Bacon, mere experimentation is repetitive and blind. It cannot reach novelty. Moreover, lucky hits have the characteristic of being singular, bare and irreproducible. From this perspective, "chance" [sortes] can only happen at the end of a disciplined process of inquiry. To the trained experimenter, "chance" appears as crowning a long, disciplined and painstaking process of discovery.

Taken as rules, or even as operational procedures, Bacon's eight "modes" of experientia literata are at once too general and too empty to constitute the skeleton of a good inquiry. But the point is that they were never meant to be rules in that particular sense. As Bacon's own examples show, the eight "modes" were meant to describe experimental practices. They read as attempts to formalize and extend patterns of "good and exact inquiry" and to generalize them into a quite sophisticated methodology of experimentation. 


\section{Conclusion}

In Bacon's natural histories, experiments come in series and constitute the matter of historia and inquisitio. Such series are constructed with the help of a sophisticated methodology guiding the experimental practices. This is what distinguishes the true experimental philosopher from the mere empiric; and the educated, literate experience from experience "in its infancy." In this paper I have explored some of the methodological elements Bacon used in order to put together such series: his directions and advice for developing new experiments and directing the reading, his "patterns of inquiry" offered as models of good experimental research, and his "good ways of experimenting," i.e., the "modes" of literate experience.

In what way does this reading of literate experience as a methodology of research explain more of the apparent conflicting features of experientia literata than the readings available so far? I believe my reading clarifies the ways in which experientia literata is both pedagogic and heuristic. On the one hand, learning the methodology is a prerequisite of good and well-disciplined (i.e. literate) experimentation. On the other hand, a more skilful researcher possesses increasingly sophisticated methodological tools for developing new experimental practices. In this way, one can say, with Bacon, that "the art of discovery grows with discovery." Its results, always provisional and subject to improvement, are the characteristic element of Bacon's natural histories:

methodologically driven experimental series with pedagogical and heuristic purposes. It is precisely the construction of such methodologically driven experimental series which 
distinguished Baconian experimentation from merely blind and repetitive experimentation and the lucky guesses of the empirics.

\section{Abbreviations:}

SEH

Bacon, Francis. 1857-74. Works, 14 vols. Edited by James

Spedding, Robert Leslie Ellis and Douglas Denon Heath. London:

Longman (repr. Stuttgart-Bad Cannstatt: Frommann, 1961-63).

OFB IV Bacon, Francis. 2000. Advancement of Learning, ed. by Michael Kiernan. Oxford: Oxford University Press.

OFB VI Bacon, Francis. 1996. Philosophical Studies c.1611-c.1619, ed. by Graham Rees and Michael Edwards. Oxford: Oxford University Press.

OFB XI Bacon, Francis. 2004. The Instauratio Magna Part II: Novum Organum and Associated Texts, ed. by a Graham Rees and Maria Wakely. Oxford: Oxford University Press.

OFB XII Bacon, Francis. 2007. The Instauratio Magna Part III: Historia Naturalis et Experimentalis: Historia Ventorum and Historia Vitae et Mortis, ed. by Graham Rees and Maria Wakely. Oxford: Oxford University Press.

OFB XIII Bacon, Francis. 2000. The Instauratio Magna: Last Writings, ed. by Graham Rees. Oxford: Oxford University Press. 
Bibliography

Anstey, Peter R. 2014. "Philosophy of Experiment in Early Modern England: The Case of Bacon, Boyle and Hooke." Early Science and Medicine 19 (2):103-132.

Bacon, Francis. 1658. Opuscula varia posthuma, philosophica, civilia, et theologica Francisci Baconi, Baronis de Verulamio, Vice-Comitis Sancti Albani. Londini: Ex officina Roger Danielis.

Bacon, Francis. 1987. Recusation des doctrines philosophiques et autres opuscules. Translated by Didier Deleule. Paris: Presses Universitaires de France.

Deleule, Didier. 1984. "Experientia-Experimentum ou le mythe du culte de l'experience chez Fracis Bacon." In Francis Bacon: Terminologia e fortuna, edited by Marta Fattori, 59-72. Rome Edizzioni del Ateneo.

Fattori, Marta. 2012. Études sur Francis Bacon. Paris: PUF.

Georgescu, Laura. 2011. "A New Form of Knowledge: Experientia Literata." Societate si Politica 5:104-121.

Giglioni, Guido. 2010. "Mastering the Appetites of Matter: Francis Bacon's Sylva Sylvarum." In The Body as Object and Instrument of Knowledge: Embodied Empiricism in Early Modern Science, edited by C.T. Wolfe and Ofer Gal, 149167. Dordrecht: Springer.

Giglioni, Guido. 2013. "Learning to Read Nature: Francis Bacon's Notion of Experiential Literacy (Experientia Literata)." Early Science and Medicine 4-5:405-434.

Jalobeanu, Dana. 2011. "Core Experiments, Natural Histories and the Art of Experientia literata: The Meaning of Baconian Experimentation." Societate si Politica 5:88104.

Jalobeanu, Dana. 2013. "Learning from Experiment: Classification, Concept Formation and Modeling in Francis Bacon's Experimental Philosophy." Revue Roumaine de Philosophie 57 (1):75-93.

Jalobeanu, Dana. 2015. The Art of Experimental Natural History: Francis Bacon in Context. Edited by Vlad Alexadrescu, Foundations of Modernity. Bucharest: Zeta Books.

Jalobeanu, Dana. 2015 (forthcoming). "Rewriting Francis Bacon's Natural History: Pierre Amboise's Translation of Sylva Sylvarum." In Natural History in Early Modern France: The Poetics of an Epistemic Genre, edited by Raphaële Garrod. Brill.

Jardine, Lisa. 1990. "Experientia literata or Novum organum? The Dilemma of Bacon's Scientific Method." In Francis Bacon's Legacy of Texts: "The Art of Discovery Grows with Discovery", edited by William A. Sessions, 47-67. New York: AMS Press.

Jardine, Lisa A. 1974. Francis Bacon, Discovery and the Art of Discourse: London: Cambridge University Press.

Mateiescu, Sebastian. 2013. "Francis Bacon on Potential Heat." Societate si Politica 7:28-44.

Pastorino, Cesare. 2011. Weighing Experience: Francis Bacon, the Inventions of the Mechanical Arts, and the Emergence of Modern Experiment, Indiana University. 
Rees, Graham. 1981. "An Unpublished Manuscript by Francis Bacon: Sylva Sylvarum Drafts and Other Working Notes." Annals of Science 38:377-412.

Rees, Graham. 1996. "Francis Bacon's Speculative Philosophy." In Cambridge Companion to Bacon, edited by Markku Peltonen, 121-145. Cambridge: Cambridge University Press.

Rees, Graham. 2007. "Introduction: The Histories in Context." In The Instauratio magna. Part 3, Historia naturalis et experimentalis : Historia ventorum and Historia vitee \& mortis, edited by Graham Rees, xvii-lxxxiii. Oxford: Clarendon Press.

Rusu, Doina-Cristina. 2013. From Natural History to Natural Magic: Francis Bacon's Sylva Sylvarum, Philosophy, Radboud University, Nijmegen.

Serjeantson, Richard. 2014. "Francis Bacon and the Interpretation of Nature in the Late Renaissance." ISIS 105:681-705.

Weeks, Sophie. 2006. "The Role of Mechanics in Francis Bacon's Great Instauration." In Philosophies of Technology: Francis Bacon and his Contemporaries, edited by Gisela Engel Claus Zittel, Romano Nani, Nicole C. Karafilys, 133-196. Brill: Brill Academic Publisher.

Weeks, Sophie. 2007. Francis Bacon's Science of Magic, Department of Philosophy, University of Leeds, Leeds. 